\title{
Association of childhood mortality with housing status and unemployment
}

\author{
MARY E. BRENNAN AND R. LANCASHIRE \\ From the West Midlands Regional Health Authority and Department of Social Medicine, Birmingham \\ Medical School, Birmingham
}

SUMMARY The association between mortality at the ages of 0-4 and 5-14 years in the county boroughs of England and Wales for 1971, using Kendall's correlation technique, and a variety of socioeconomic indicators, was computed. Kendall's partial correlation technique was used to determine whether any association remained when the effect of social class and unemployment was kept constant. At ages 0-4 years there was a significant and positive association between mortality and low socioeconomic position, high density housing, inadequate housing amenities, and the unemployment rate $(P<0.001)$. A significant association with the housing variables remained when the effect of socioeconomic status and unemployment was kept constant. Between the ages 5-14 years there was a statistically significant association $(P<0.001)$ between mortality and housing density which was eliminated when the effect of social class was held constant. There was no association between unemployment and mortality in this age group.

In the Court Report (1976) the effect of social class, poverty, and environment on the health of children was examined but, except for social class, it was not possible to state whether these factors had a direct association with ill health in children. Recent work has demonstrated that there is still a positive gradient between socioeconomic position and mortality. Adelstein and White (1976) have shown that for the age group 1-4 years the rate is more than doubled from social class I to social class V. In the age group 5-9 years a similar effect occurs and in the age group 10-14 years the increase is over one-third. Lambert (1976) has demonstrated that although the total mortality rate has fallen, the decrease in mortality is substantially less within social class $\mathrm{V}$ than it is in social class $\mathrm{I}$. However, socioeconomic status may be an indicator only of other types of deprivation and its use as a sole indicator may be misleading (British Medical Journal, 1976).

In an interesting study 30 years ago (Woolf and Waterhouse, 1945; Woolf, 1947) it was shown that infant mortality was related to unemployment, low pay, and overcrowding. These results were disbelieved at the time and the contention of the authors that the infant mortality rate among deprived groups could be reduced using the medical techniques of that time to a figure of just above 20 from over 100, was regarded as unfounded
(British Medical Journal, 1945). This aim haso recently been achieved, but there still remain differences in the rate between various socioeconomic groups.

This paper sets out to determine whether mortality in the first five years of life (excluding stillbirths) is still positively associated with various indications of socioeconomic deprivation in county boroughs-such as, an increase in density within households, the provision of amenities in houses, and the proportion of unemployed. It examines whether any association is maintained when the effect of social class is kept at a constant level.

Therefore, as socioeconomic data derived directly from individual income and housing are often difficult to obtain and are unreliable, a geographical analysis using census data from county boroughs in England has been undertaken. This method has several advantages (Simon, 1974; Brennan and Hebel, 1975) and although the administrative areas did not present entirely homogeneous socioeconomic characteristics within each borough, there was sufficient variation between them to explore the socioeconomic mechanisms.

\section{Method}

The mortality rates for various age groups-that is, 0-4 and 5-14 years-were obtained from the Office 
of Population Censuses and Surveys for each county and metropolitan borough in England for 1971, with the exception of the City of London. For each county borough the following characteristics were abstracted from the 1971 census: (a) housing density, the percentage of houses with one person and with one and a half persons or more per room; (b) housing amenities, the percentage of houses with no hot water, no bath, no inside lavatory, and with exclusive use of amenities; (c) tenure, percentages of owner occupiers and council house tenants; (d) the proportion of those economically active; $(e)$ the proportion of those unemployed. The average rating value for domestic establishments for each county borough was also obtained from the 1971 report of the Municipal Treasurers. The proportions of the male population aged between 15 and 64 years in social classes I, IV, and V were obtained from the census. The definitions were the standard ones used by the Registrar General.

A rank correlation technique was used to ascertain which social and economic factors had an independent association at different ages. Each county borough was placed in ranking order from one to 111 for each variable and Kendall's rank correlation coefficient was computed between mortality rates at specific ages and the factor under consideration.

This particular method was chosen instead of the product moment coefficient because it was not likely the relations were strictly linear and the distribution of some of the variables was skewed. It also had the additional advantage that it could be used to determine partial correlation coefficients so that the association between two variables could be measured while one-third was regarded as being kept constant. There is every reason to believe that for samples of this size an approximate test of significance using the standard normal distribution would give accurate results.

The association of unemployment with mortality was investigated using the partial correlation technique to hold a variety of factors constant and a similar technique was used to examine housing characteristics.

\section{Results}

The mortality rate in children aged between 0 and 4 years varied markedly between county boroughs. The mean mortality rate was 369.6 per 100000 a year, the standard deviation being $98 \cdot 2$. In boroughs outside London the mortality rate was 372.9 per 100000 a year with a standard deviation of $95 \cdot 3$. In London the mortality rate was slightly lower, $361 \cdot 5$ per 100000 a year with a standard deviation of $106 \cdot 2$ (Fig. 1).

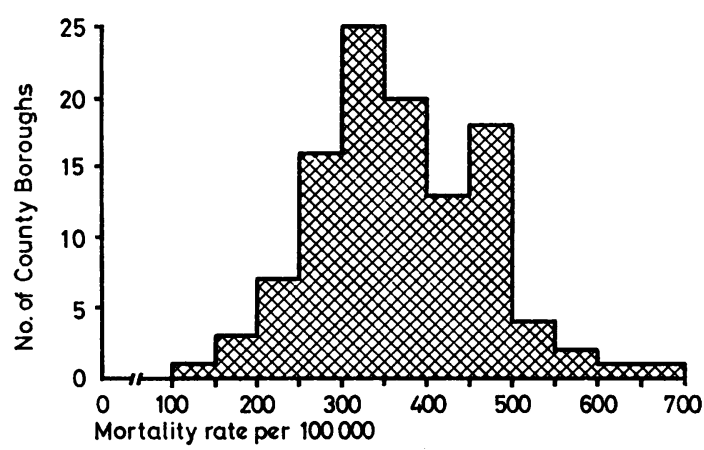

Fig. 1 Frequency distribution of mortality rate in children aged 0-4 years per 100000 (in county boroughs of England)

At ages between 5 and 14 the mean mortality was 19.4 per 100000 a year with a standard deviation of $10 \cdot 8$. The means of boroughs in and out of London were almost identical-that is, $19 \cdot 5$ and $19 \cdot 2$.

The range of mortality for both age groups was large. In the younger range the county borough of Canterbury had a mortality rate of 142.9 and Solihull 176.5 per 100000 a year, while Camden's mortality rate was 673.1 and Rochdale's was 567.9 per 100000 a year. In the older group six boroughs registered no deaths, including Barrowin-Furness, Southend-on-Sea and Great Yarmouth, while again Camden had a high rate, $49 \cdot 3$ and Grimsby an even higher rate of 59.2 per 100000 a year. The mortality rate in the industrial towns of Yorkshire and Lancashire was on average very much higher than that of the country as a wholefor example 425.9 per 100000 a year for the younger age group. Boroughs further north had a mean of 389.4 per 100000 a year.

The mortality rates were correlated against various housing characteristics and the results are shown in Table 1. The association was marked in the younger age group between most of the variables and the mortality rates, and reached a significance level of $0.1 \%$. However, in the age group above five years only housing density had a marked effect. A similar pattern was demonstrated when the association was computed between mortality and employment indices, the unemployment rate showing a marked association $(P<0.001)$ in children under five years (Table 2).

The percentage of households with one or more person per room varied from $4.6 \%$ in Solihull to $18.2 \%$ in Tower Hamlets. The lower quartile point was $12.9 \%$. The mean mortality for the lower quartile for the younger age group was 284.7 and for the higher quartile 420.0 per 100000 
Table 1 Correlation of housing variables derived from the census and housing statistics (1971) with mortality rates

\begin{tabular}{|c|c|c|}
\hline \multirow{3}{*}{$\begin{array}{l}\text { Variable (as a proportion of } \\
\text { total population) }\end{array}$} & \multirow{2}{*}{\multicolumn{2}{|c|}{$\begin{array}{l}\text { Kendall's rank } \\
\text { correlation coefficient }\end{array}$}} \\
\hline & & \\
\hline & $0-4$ & $5-14$ \\
\hline $\begin{array}{l}\text { Density } \\
\text { One or more persons living per room } \\
1 \frac{1}{2} \text { or more persons living per room }\end{array}$ & $\begin{array}{l}0.416 * * * \\
0.391 * * *\end{array}$ & $\begin{array}{l}0 \cdot 217 * * * \\
0 \cdot 218 * * *\end{array}$ \\
\hline $\begin{array}{l}\text { Amenities } \\
\text { No hot water } \\
\text { No bath } \\
\text { No inside lavatory }\end{array}$ & $\begin{array}{l}0 \cdot 304 * * * \\
0 \cdot 369 * * * \\
0 \cdot 301 * * *\end{array}$ & $\begin{array}{l}0 \cdot 140^{*} \\
0 \cdot 154^{*} \\
0 \cdot 068 \mathrm{NS}\end{array}$ \\
\hline $\begin{array}{l}\text { Tenure } \\
\text { Exclusive use of amenities } \\
\text { Owner occupier } \\
\text { Percentage of council house tenants }\end{array}$ & $\begin{array}{r}-0 \cdot 355 * * * \\
-0 \cdot 268 * * * \\
0 \cdot 193 * * *\end{array}$ & $\begin{array}{l}-0.156^{*} \\
-0.147^{*} \\
0.093 \mathrm{NS}\end{array}$ \\
\hline $\begin{array}{l}\text { Rating } \\
\text { Average value per household }\end{array}$ & $-0 \cdot 164 *$ & $-0.02 \mathrm{NS}$ \\
\hline $\begin{array}{c}* *(P<0.001) \\
*(P<0.01) \\
*(P<0.05) \\
\text { NS Not significant }\end{array}$ & & \\
\hline
\end{tabular}

Table 2 Correlation of employment variables derived from census with mortality rates for county boroughs in England for the year 1971

\begin{tabular}{|c|c|c|}
\hline \multirow{3}{*}{$\begin{array}{l}\text { Variable (as a proportion of male } \\
\text { working population) }\end{array}$} & \multicolumn{2}{|c|}{$\begin{array}{l}\text { Kendall's rank } \\
\text { correlation coefficien }\end{array}$} \\
\hline & \multicolumn{2}{|c|}{ Age group (years) } \\
\hline & $0-4$ & $5-14$ \\
\hline $\begin{array}{l}\text { Economically active } \\
\text { Out of employment }\end{array}$ & $\begin{array}{r}-0 \cdot 001 \mathrm{NS} \\
0 \cdot 336 * * *\end{array}$ & $\begin{array}{l}-0.079 \mathrm{NS} \\
-0.123 \mathrm{NS}\end{array}$ \\
\hline
\end{tabular}

a year, a percentage increase of $47 \cdot 5 \%$ of the highest quartile mean mortality over the lowest quartile mean mortality. Only a few London boroughs were in the middle ranges, the majority either being in the lowest quartile (12) or the highest (10). The older age group showed a similar pattern (see Figs 2 and 3).

The unemployment rate for men ranged from $2.1 \%$ in Solihull to $10.6 \%$ in Liverpool. The lower quartile point was $4.0 \%$ and the higher $6.6 \%$. The mean mortality for the lowest quartile for the younger age group was $302 \cdot 3$ and for the highest quartile 413.3 per 100000 a year, a percentage increase of $36.7 \%$ of the highest quartile mean mortality over the lowest quartile mean mortality. Only one London borough was found in the highest quartile.

It could be argued that these effects were only an expression of social class. Therefore the association between social class census indicators and mortality was computed. A strongly positive association was demonstrated between high mortality and low socioeconomic position $(P<0.001)$

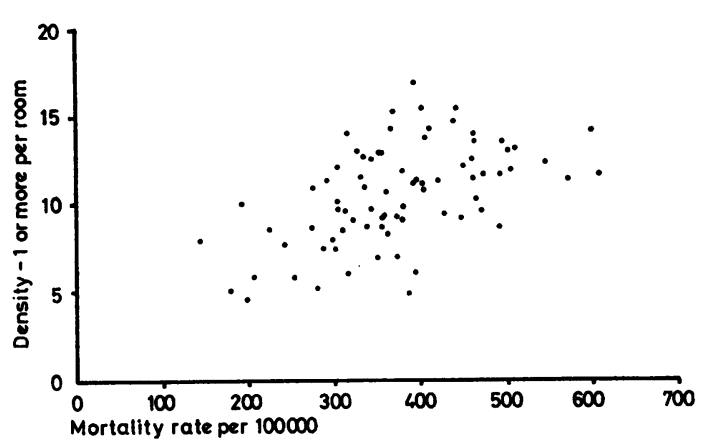

Fig. 2 Mortality rate outside London in children aged o $0-4$ years by housing density (proportion in area living one or more per room).

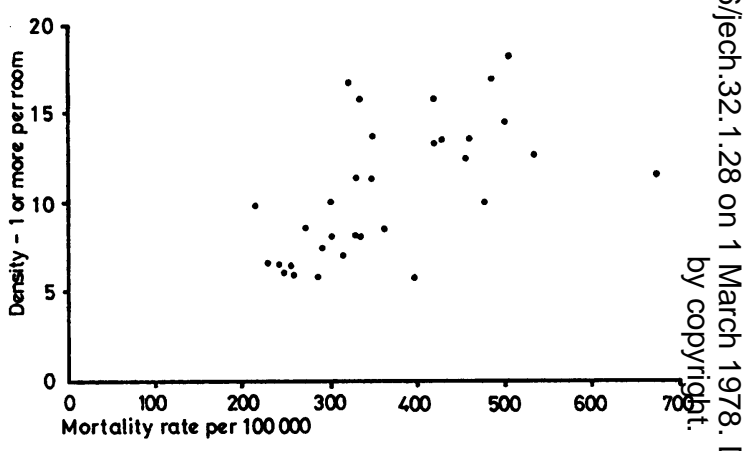

Fig. 3 Mortality rate in London in children aged 0-4 years by housing density (proportion in area living one or more per room).

for the age group under five years, with the older age group showing a less marked association.

The percentage of men in social class $V$ occupations ranged from $3.4 \%$ in the London borough of Harrow to $19.9 \%$ in Tower Hamlets. The lowest quartile point was $7 \cdot 3 \%$ and the highest $10.9 \%$. The mean mortality for the lower quartile for the younger age group was $301 \cdot 2$ and for the highest 420.0 per 100000 a year, a percentage increase of $39 \%$ of the highest quartile mean mortality over the lowest quartile mean mortality. The highest quartile contained only four London boroughs, the lowest contained 17. However, when Kendall's partial correlations were computed, eliminating the social class $V$ effect, although other socioeconomic variables became relatively unimportant for the age group over four years, in young children all of the indicators of socioeconomic deprivation retained an association with mortality with a high level of significance (Table 3). 
Table 3 Correlation of housing and employment variables derived from census and housing statistics (1971) with mortality rates (1971) for the age group from birth to four years holding the effect of social class constant

\begin{tabular}{|c|c|c|}
\hline $\begin{array}{l}\text { Variable as a proportion of } \\
\text { total population }\end{array}$ & $\begin{array}{l}\text { Kendall's rank } \\
\text { correlation with } \\
\text { social class }\end{array}$ & $\begin{array}{l}\text { Partial correlation } \\
\text { holding social } \\
\text { class constant }\end{array}$ \\
\hline $\begin{array}{l}\text { Density } \\
\text { One or more persons } \\
\text { living per room } \\
1 \frac{1}{2} \text { or more persons } \\
\text { living per room }\end{array}$ & $\begin{array}{l}0 \cdot 530 * * * \\
0 \cdot 330 * * *\end{array}$ & $\begin{array}{l}0 \cdot 300^{* * *} \\
0 \cdot 315^{* * *}\end{array}$ \\
\hline $\begin{array}{l}\text { Amenities } \\
\text { No hot water } \\
\text { No bath } \\
\text { No inside lavatory } \\
\text { Exclusive use of amenities }\end{array}$ & $\begin{array}{r}0.455 * * * \\
0.593 * * * \\
0.586 * * * \\
-0.448 * * *\end{array}$ & $\begin{array}{c}0 \cdot 182^{* *} \\
0 \cdot 228^{*} \\
0 \cdot 140^{*} \\
-0 \cdot 246^{* * *}\end{array}$ \\
\hline $\begin{array}{l}\text { Tenure } \\
\text { Owner occupier } \\
\text { Council house tenants }\end{array}$ & $\begin{array}{l}-0.355 * * * \\
-0.455 * * *\end{array}$ & $\begin{array}{l}-0.171 * * \\
0.050 \mathrm{NS}\end{array}$ \\
\hline Unemployment & $0.520 * * *$ & $0 \cdot 192 * *$ \\
\hline $\begin{array}{c}* * *(\mathrm{P}<0.001) \\
*(\mathrm{P}<0.01) \\
*(\mathrm{P}<0.05) \\
N S \text { Not significant }\end{array}$ & & \\
\hline
\end{tabular}

When the effect of the unemployment rate on housing variables was eliminated by using Kendall's partial correlation technique, it was demonstrated that these factors appeared to have an independent association one from another with mortality (Table 4).

The association of the average rating value for domestic households with mortality was also computed. A figure of $0.164(P<0.01)$ was obtained. However, when a partial correlation was computed eliminating the effect of social class, as defined by the proportion of the male working population in class $\mathrm{V}$, the association was no longer significant. A similar result occurred when the effect of housing density was eliminated using a partial correlation, a figure of only -0.093 being obtained.

There were some slight variations between the London boroughs and the rest of the country. The association of the proportion of unemployed men and mortality was significant only outside London,

Table 4 Correlation of selected housing variables derived from census with mortality rates (1971) for the age group from birth to four years holding the effect of the unemployment rate constant

\begin{tabular}{lll}
\hline $\begin{array}{l}\text { Variable (as a proportion of } \\
\text { total population) }\end{array}$ & $\begin{array}{l}\text { Kendall's rank } \\
\text { correlation with } \\
\text { unemployment rate }\end{array}$ & $\begin{array}{l}\text { Partial correlation } \\
\text { holding unemploy- } \\
\text { ment rate constant }\end{array}$ \\
\hline $\begin{array}{l}\text { Density } \\
\text { One or more persons } \\
\text { living per room }\end{array}$ & $0.423^{* *}$ & $0.320^{* *}$ \\
$\begin{array}{l}\text { Amenities } \\
\begin{array}{l}\text { No bath } \\
\text { Exclusive use of } \\
\text { amenities }\end{array}\end{array}$ & $0.419 * *$ & $0.267^{* *}$ \\
\hline$* *$ (P <0.01) & $-0.336^{* *}$ & $-0.273^{* *}$ \\
\hline
\end{tabular}

probably reflecting the low unemployment rate in London. However, the association of particular amenities with mortality did not reach statistically significant levels in London, although the proportion with an exclusive use of amenities still had a significant effect at the $1 \%$ level.

The effect of atmospheric pollution was not measured, but adjacent boroughs which presumably could not have had widely different pollution levels varied markedly. This relationship was clearly demonstrated in London where, for instance, in central London in the youngest age group, Greenwich had a mortality rate of $329 \cdot 2$, Islington 333.3 , and Westminster 299.0 per 100000 a year, while the mortality rate for Lewisham was $427 \cdot 8$, Tower Hamlets $478 \cdot 6$, and Camden 673.1 per 100000 a year. However, pollution may have an effect particularly in the northern industrial towns, being synergistic with housing density.

\section{Discussion}

\section{METHOD}

The data were collected from all county boroughs in England for a year; this has several implications for evaluating the results. Any effect demonstrated would be typical of urban areas and not rural ones in England. If the effect was different in type or magnitude in smaller boroughs, there would be some distortion because the results were not weighted for population. However, if the smaller boroughs had been eliminated, it is possible that an even more serious distortion would have occurred because many of the boroughs in London and the north-west would not have been included. Some statistical variation is certain to occur if mortality statistics are collated for only one year for individual boroughs, and therefore results of this kind should be treated with caution. However, using the rank correlation technique such statistical variation should not markedly influence the correlation achieved between different variables for the county boroughs as a whole.

\section{RESULTS}

Although the association between social class of the father and child mortality is well known and documented (Adelstein and White, 1976; Lambert, 1976), the relationship between child mortality, housing deprivation, and unemployment was not known. In various studies carried out on data from before the second world war, this relationship was shown (Woolf and Waterhouse, 1945), but we are not aware of any studies of this kind since the inception of the welfare state. The mortality during the 1930s had been shown to vary with the density 
per room (housing density) rather than the density per acre (population density) (Stocks, 1934). An increase in the initial and secondary attack rate of various infectious diseases had also been elucidated and houses without facilities had been shown to be associated with a high risk of indigestion and diarrhoea (Britten, 1942), but there is an assumption that at the present time, because of the increase in living standards, any effect of this kind would now only be marginal.

However, in this study housing density and housing facilities are shown to have a highly significant association with child mortality under five years and this remains true when the effect of social class and unemployment is eliminated. This is an important finding because it supports the hypothesis that much of the difference in mortality between groups in different social circumstances and geographical areas is related to environmental factors.

In 1971, about one-tenth of persons were living in overcrowded conditions (one or more per room) and about one-fifth of households did not have exclusive use of hot water, a fixed bath, and an inside lavatory (General Household Survey, 1976). In 1976 about one in 20 dwellings was unfitthat is, out of 643000 that were occupied. Overcrowding reflects income patterns in a market economy because of the inability of those with low incomes to purchase additional units and also because a larger number of adult dependants may be living with low income families (Cutright, 1971; Greenberg et al., 1973). Even in cases where the family is living in council housing, families on low incomes are more likely to be housed in inferior and overcrowded accommodation (Rutter and Madge, 1973). For instance, when the father is unemployed, the family is twice as likely to live in overcrowded conditions.

In this study, unemployment of the father was shown to have a highly significant association with mortality in young children, even when the effect of social class was eliminated. This confirms previous work which indicated that morbidity was increased in the children of unemployed fathers (Brennan and Stoten, 1976), so that in manual workers the admission rate to a paediatric hospital was doubled. This was not a result of a higher level of demand, but a greater need for the service in this group. The effect was almost entirely restricted to children under two years presenting with respiratory infections and, from examining the data, the effect was almost certainly reflected by disposable income levels. Unemployment as such has some direct effect on the health of the men (Taylor and Pocock,
1969; Kasl and Cobb, 1970), but the effect on children is probably related to an abrupt decrease in living standards, particularly diet and heating.

Unemployment in the 1930s was high, while in 1971 it was low. The effect of high levels of unemployment cannot be directly estimated from these results. However, the association was strongly positive on both occasions. The data on morbidity was collected at a time of a fairly high rate of unemployment in the area where the study was undertaken (Brennan and Stoten, 1976), indicating that the association would probably retain a high level of statistical significance at a time of relatively high unemployment. The social class group most affected was social class $\mathrm{V}$ which was one of the reasons why it was decided to use this as the main class indicator, in order to differentiate the effect of the proportion of social class $V$ from the effect of the proportion of adult unemployed men. Therefore to estimate the standard of living for children in any area, the proportion of manual workers or class $\mathrm{V}$ workers employed in that area is not a sufficiently sensitive indicator. The housing characteristics and unemployment rate need also to be considered.

It could be argued that this pattern of mortalit in children is dependent on latitude. However, the northern boroughs had a slightly lower mortalit rate than those in Yorkshire and Lancashire, whic confirms previous work that the effect of latitude is marginal (Stocks, 1934). This association may also be related to atmospheric pollution (Hunt and Cross, 1975; World Health Organisation, 1974). However, when the results are taken for London separately, the association between housing characteristics and mortality attains a higher level of significance than for the country as a whole, which is a finding that indicates atmospheric pollution is not the most important factor. This is not true for unemployment which is not surprising as the rate in all the London boroughs was low at this time.

In those areas with a higher mortality rate, the services on the whole are less well developed than in other places (Townsend, 1974) with less revenue and less capital investment. On the whole, the association is indirect, but it is now recognised that such areas require more investment, both in absolute and relative terms (Department of Health and Social Security, 1976). While the Court Report (1976) argues that radical restructuring of paediatric and obstetric services is urgently required, the need for increased service provision in areas of socioeconomic deprivation should be a fundamental criterion to be used to formulate future policy and 
although it may be true that the main factors influencing the association of unemployment, housing and health in young children are not medical but social (Wambem and Piland, 1973; Babbage, 1974), the implications for the NHS cannot be ignored, whether the problem is viewed as having implications for the preventive or the curative services.

The help of the technicians in the Department of Social Medicine, University of Birmingham, was greatly appreciated and the co-operation of the staff of Office of Population Censuses and Surveys was essential in the preparation of this paper.

Reprints from Dr M. Brennan, Community Medicine (Planning), West Midlands Regional Health Authority, 146 Hagley Road, Birmingham B16 9PA.

\section{References}

Adelstein, A., and White, G. (1976). Causes of children's deaths analysed by social class. Child health. A collection of studies. Studies on Medical and Population Subjects, General Register Office, 31, 25-42.

Babbage, T. (1974). A critical assessment of housing policy for new local government. (b) Stress and distress in inner city areas. Royal Society of Health Journal, 94, 189-194.

Brennan, M. E., and Hebel, R. (1975). Socio-economic factors associated with unwanted births to married women: a geographical analysis using census indicators. Journal of Biosocial Science, 7, 463-472.

Brennan, M., and Stoten, B. (1976). Children, poverty, and illness. New Society, 36, 681-682.

British Medical Journal (1945). Editorial: Infant mortality and social conditions. British Medical Journal, 2, 392-393.

British Medical Journal (1976). Editorial: Children who die through social disadvantage. British Medical Journal, 2, 962-963.

Britten, R. H. (1942). New light on relation of housing to health. American Journal of Public Health and the Nation's Health, 32, 193-199.
Court Report (1976). Fit for the Future. Report of the Committee on Child Health Services. HMSO: London.

Cutright, P. (1971). Income and family events. Journal of Marriage and the Family, 33, 161.

Department of Health and Social Security (1976). Report of the Resource Allocation Working Party. Sharing Resources for Health in England. HMSO: London.

General Household Survey (1976). Social Trends, p. 152. HMSO: London.

Greenberg, M. A., Nelson, K. E., and Curnow, B. W. (1973). A study of the relationship between sudden infant death syndrome and environmental factors. American Journal of Epidemiology, 98, 412-422.

Hunt, V. R., and Cross, W. L. (1975). Infant mortality and the environment of a lesser metropolitan county: a study based on births in one calendar year. Environmental Research, 9, 135-151.

Kasl, S. V., and Cobb, S. (1970). Blood pressure changes in men undergoing job loss: a preliminary report. Psychosomatic Medicine, 32, 19-38.

Lambert, P. (1976). Perinatal trends: social and environmental factors. Population Trends, 4, 4-11.

Rutter, M., and Madge, N. (1973). Cycles of Disadvantage. Heinemann: London.

Simon, J. L. (1974). The Effects of Income on Fertility. Carolina Centre Monograph No. 19. University of North Carolina.

Stocks, M. (1934). Association between mortality and density of housing. Proceedings of the Royal Society of Medicine, 27, 1127-1146.

Taylor, P. J., and Pocock, S. J. (1969). Post-war trends in sickness absence and unemployment in Great Britain. Lancet, 2, 1120-1122.

Townsend, P. (1974). Inequality and the health service. Lancet, 1, 1179-1190.

Wambem, D. B., and Piland, N. F. (1973). Effects of improved housing on health in south Dos Palos, California. Health Services Reports, 88, 47-58.

Woolf, B. (1947). Studies on infant mortality, Part II. Social aetiology of stillbirths and infant deaths in county boroughs of England and Wales. British Journal of Preventive and Social Medicine, 1, 73-125.

Woolf, B., and Waterhouse, J. (1945). Studies on infant mortality: influence of social conditions in county boroughs of England and Wales. Journal of Hygiene, 44, 67-98.

World Health Organisation (1974). The Uses of Epidemiology in Housing Programmes and in Planning Human Settlements. Technical Report Series No. 544. WHO: Geneva. 